\title{
PENGARUH STRES KERJA DAN KEPUASAN KERJA TERHADAP KINERJA KARYAWAN
}

\author{
Christian Sahat Parasian dan I Gede Adiputra
}

Program Studi Manajemen Fakultas Ekonomi Universitas Tarumanagara, Jakarta <Email: csahatparasian@gmail.com dan gedea@fe.untar.ac.id>

\begin{abstract}
Abstrak: Penelitian ini bertujuan untuk menngetahui pengaruh stres kerja dan kepuasan kerja terhadap kinerja karyawan pada PT. International Total Service \& Logistics. Perusahaan International Total Service \& Logistics merupakan perusahan agensi pelayaran yang bergerak dibidang logistik. Pengumpulan data dalam penelitian ini dengan melakukan penyebaran kuesioner terhadap 80 responden melalui media Google Form. Penelitian ini menggunakan metode pendekatan non-probability sampling dengan teknik sampling jenuh. Teknik analisis data yang digunakan adalah analisis deskriptif, uji asumsi klasik, uji koefisien determinasi, uji analisis jalur, uji hipotesis yang diolah menggunakan software IBM SPSS versi 26. Pada penelitian ini, didapat hasil yang menunjukan bahwa stres kerja tidak terdapat pengaruh secara signifikan terhadap kinerja karyawan, dan kepuasan kerja terdapat pengaruh secara signifikan terhadap kinerja karyawan.
\end{abstract}

Kata Kunci: Stres Kerja, Kepuasan Kerja, Kinerja Karyawan

\begin{abstract}
This study aims to determine the effect of job stress and job satisfaction on employee performance at PT. International Total Service \& Logistics. The International Total Service \& Logistics company is a shipping agency company engaged in logistics. Collecting data in this study by distributing questionnaires to 80 respondents (through Google Form media). This study uses a non-probability sampling approach with a saturated sampling technique. The data analysis technique used is descriptive analysis, classical assumption test, coefficient of determination, path analysis test, hypothesis testing which is processed using IBM SPSS version 26 software. In this study, the results showed that work stress had no significant effect on performance. employees, and job satisfaction have a significant effect on employee performance.
\end{abstract}

Keywords: Job Stress, Job Satisfaction, Employee Performance 


\section{LATAR BELAKANG}

Kemajuan dari perekonomian dunia yang memasuki era globalisasi semakin menunjukan titik terang. Adanya Kerjasama dalam pemenuhan kebutuhan setiap negara dan pulau menunjukan bahwa kebergantungan setiap negara dengan negara, pulau dengan pulau lain. Dalam memenuhi bidang logistik, pada saat ini pelayaran laut masih banyak diminati dikarenakan tarif yang lebih murah daripada penerbangan udara. International Maritime Organization (IMO) yang merupakan agency dari United Nations mengemukakan bahwa, pelayaran laut telah menjadi darah kehidupan ekonomi dunia, dengan bukti bahwa bisnis pengiriman barang di dunia 90 persen dilakukan oleh perusahaan pelayaran laut (IMO, 2012).

Namun, persaingan di dunia bisnis terkadang menjadi semakin sengit. Perubahan lingkungan yang menjadi penyebab utama persaingan bisnis semakin sulit diprediksi. Singkatnya, perusahaan yang tidak bisa bersaing akan tersingkir. Perusahaan yang tidak dapat bertahan dalam persaingan adalah perusahaan yang tidak dapat berdiri dalam organisasi kompetitif yang akan terus eksis di era globalisasi.

Tanpa adanya sumber daya manusia, organisasi tidak dapat mewujudkan eksistensinya. Sumber daya manusia yang mampu berkontribusi kepada perusahaan adalah sumber daya manusia yang memiliki kompetensi dan kualitas agar mampu bertahan dalam persaingan (Lingga, 2019). Hal serupa juga diungkapkan oleh Malik (2019) bahwa sumber daya manusia yang memiliki komitmen dan tanggung jawab yang dapat meningkatkan kinerjanya. Begitu pentingnya sumber daya manusia untuk mendukung kesuksesan perusahaan dalam mencapai tujuan, maka permasalahan terkait dengan sumber daya manusia harus mendapatkan prioritas untuk diselesaikan sehingga mampu meningkatkan kinerja sumber daya manusia. Menurut Hasibuan (2013:38) mengungkapkan bahwa kinerja karyawan adalah suatu hasil yang dicapai oleh seseorang dalam melaksanakan tugas-tugas yang dibebankan kepadanya. Namun, tidak sedikit perusahaan menuntut sumber daya manusianya untuk lebih meningkatkan kemampuan dan keahliannya. Tanpa disadari, hal ini dapat membuat stres karyawan terjadi, dan mempengaruhi kepuasan kerja dan kinerja karyawan tersebut. Stres akan terjadi bila individu tidak mampu memahami keterbatasannya terhadap suatu hal. Stres kerja dan kepuasan kerja karyawan memiliki pengaruh terhadap kinerja karyawan. Stres kerja dapat mempengaruhi peningkatan atau penurunan kinerja karyawan, tergantung dari bagaimana respon karyawan terhadapnya. Pada saat tertentu, stres kerja diperlukan untuk mendorong karyawan agar bekerja lebih keras, namun stres kerja yang tinggi dapat menurunkan kinerja karyawan. Di sisi lain, kepuasaan kerja karyawan terhadap pekerjaannya dapat memberikan hasil dan tujuan kinerja karyawan yang telah ditetapkan perusahaan. Hal ini perlu diperhatikan perusahaan, karena dengan rendahnya tingkat stres kerja dan tingginya kepuasan kerja karyawan dalam bekerja maka hasil kinerja karyawan yang tinggi akan tercipta sehingga dapat memenuhi kebutuhan perusahaan yang telah ditetapkan.

Stres didefinisi oleh Robbins dan Judge (2015:582) sebagai suatu kondisi dinamis dimana individu berkonfrontasi dengan peluang, tuntutan, atau sumber daya yang terkait dengan keinginannya dan dimana luaran dipersepsikan sebagai suatu hal yang penting dan tidak pasti. Secara garis besar, apabila tingkat stres terlalu tinggi, maka dapat mengancam kemampuan seseorang dalam menghadapi lingkungan. Robbins and Judge (2008:377) menjelaskan juga bahwa salah satu dampak stres secara psikologis adalah dapat menurunkan kepuasan kerja karyawan dimana kepuasan kerja merupakan sikap emosional yang menyenangkan dan mencintai pekerjaannya. Ostroff (1992) mengemukakkan bahwa kepuasan kerja adalah bentuk dari sikap karyawan pada pekerjaan secara langsung mengikat kebutuhan individu sehingga semakin tinggi kepuasan kerja mampu meningkatkan keefektifitasan organisasi. Selain itu, McNamara (1999) juga menyatakan bahwa kinerja merupakan salah 
satu hasil dari kepuasan kerja. Ma et al. (2012) juga menyatakan bahwa kinerja merupakan salah satu outcome dari kepuasan kerja. Hal tersebut membuktikan bahwa kepuasan kerja memiliki hubungan yang positif dengan kinerja karyawan itu sendiri.

Sedangkan, didukung oleh penelitian Pincherle (1972) stres kerja bersifat menganggu kinerja dan semakin tinggi stres kerja maka semakin tinggi pula tingkat gangguan pada kinerja. Selain itu, Shahu dan Gole (2008:237) juga menyatakan bahwa stres merupakan kondisi mental dan fisik yang terjadi oleh gangguan gangguan yang berpengaruh terhadap produktivitas kerja, efektivitas, kesehatan karyawan, dan kualitas kerja. Hal ini akan berdampak terhadap penurunan kinerja seorang karyawan. Pendapat tersebut secara jelas menunjukkan bahwa terdapat korelasi negatif antar stres kerja dan kinerja dimana ketika stres kerja tinggi maka kinerja semakin rendah.

Persaingan dunia bisnis khususnya perusahaan logistik semakin ketat, hal tersebut didukung oleh meningkatnya permintaan dan kebutuhan manusia itu sendiri. Kinerja karyawan pada PT International Total Service \& Logistics menjadi perhatian khusus yang harus dipertimbangkan oleh perusahaan untuk menghadapi tantangan perusahaan dan tercapainya tujuan yang telah ditetapkan oleh perusahaan. Maka dari itu, pentingnya tugas perusahaan untuk selalu memperhatikan dalam pemberian beban kerja yang dapat mempengaruhi stres karyawan dan memperhatikan tingkat kepuasan kerja karyawan tersebut yang dapat menghasilkan kinerja karyawan yang maksimal yang diharapkan oleh perusahaan. Berdasarkan fenomena dan penelitian terdahulu yang telah dibahas, maka dari itu tujuan dari penulis dalam penelitian ini adalah untuk mengetahui hasil pengaruh stres kerja dan kepuasan kerja terhadap kinerja karyawan pada PT. International Total Service \& Logistics di Indonesia.

\section{KAJIAN TEORI}

Teori yang dikenal dengan Convervation of Resources (COR) Theory atau teori konservasi sumber daya yang berarti bahwa seseorang akan selalu berusaha untuk memperoleh dan menjaga ataupun melindungi sumber daya yang berharga yang dimiliki oleh orang tersebut dari sebuah gangguan ataupun ancaman. Keadaan di mana individu merasa terancam (threaten) kehilangan sumber daya yang dimilikinya akan mengakibatkan kejenuhan (burnout) dan halhal yang berhubungan dengan stres kerja, ketidakpuasan kerja, depresi atau tekanan (Hobfoll \& Shirom, 1993). Sedangkan, teori yang dikemukakan oleh Georgopoulos et al. (1957) yang disebut Path Goal Theory menyatakan bahwa kinerja adalah fungsi dari facilitating Process dan Inhibiting process. Prinsip dasarnya adalah kalau seseorang melihat bahwa kinerja yang tinggi itu merupakan jalur (Path) untuk memuaskan kebutuhan (Goal) tertentu, maka ia akan berbuat mengikuti jalur tersebut. Selanjutnya, menurut Teori Herzberg et al. (1959) seseorang mengemukakan dua macam kelompok faktor kebutuhan yaitu faktor motivational dan faktor hygiene. Maka dari itu, Herzberg menetapkan teori dua faktor dari teori kepuasan kerja yang menyatakan bahwa prinsip kepuasan dan ketidakpuasan merupakan bagian dari kelompok variabel yang berbeda. Teori ini membedakan dua kelompok faktor pekerjaan. Kelompok yang pertama berhubungan dengan aspek intrinsik. Kelompok kedua berhubungan dengan lingkungan pekerjaan atau faktor ektrinsik pekerjaan

\section{Stres Kerja}

Griffin dan Moorhead (2013:181) mendefinisikan stres sebagai respon adaptif seseorang terhadap rangsangan yang menempatkan tuntutan psikologis atau fisik yang berlebihan padanya. Sedangkan, menurut Hasibuan (2003:203) stres adalah kondisi ketegangan yang mempengaruhi emosi, proses berpikir, dan kondisi seseorang. Berdasarkan definisi mengenai stres kerja menurut para ahli diatas dapat disimpulkan bahwa stres kerja merupakaan 
ketegangan yang dialami oleh karyawan karena terjadinya ketidakseimbangan antara kemampuan karyawan dengan tuntutan pekerjaan yang berlebihan. Alat ukur yang digunakan pada penelitian ini sebagai indikator stres kerja yang digunakan oleh Prasetio et al (2019).

\section{Kepuasan Kerja}

Fathoni (2006:174), mengungkapkan kepuasan kerja adalah sikap emosional yang menyenangkan dan mencintai pekerjaannya. Namun, menurut Robbins (2007:108), jika seseorang tidak mendapatkan kepuasan kerja, hal itu dapat diungkapkan melalui pengunduran diri, mudah mengeluh, tidak patuh, mencuri peralatan kerja, serta menghindari tanggung jawab dalam bekerja. Pemaparan pendapat menurut para ahli dan peneliti tentang kepuasan kerja dapat disimpulkan bahwa kepuasan kerja merupakaan keadaan emosional atau perasaan setiap individu karyawan terhadap hasil yang didapat dari pekerjaan yang dilakukan. Singkatnya, kepuasaan kerja merupakan cerminan dari sikap atau perilaku karyawan dalam melakukan pekerjaan yang diberikan oleh perusahaan. Peneliti Masman dan Pamungkas (2013) mengemukakan, untuk mencapai tujuan yang ingin dicapai di dalam sebuah perusahaan atau organisasi, produktifitas yang tinggi dan kinerja yang optimal ditentukan oleh kepuasan kerja. Alat ukur yang digunakan pada penelitian ini sebagai indikator stres kerja yang digunakan oleh Prasetio et al (2019).

\section{Kinerja Karyawan}

Menurut Hasibuan (2013:38) mengungkapkan bahwa kinerja karyawan adalah suatu hasil yang dicapai oleh seseorang dalam melaksanakan tugas-tugas yang dibebankan kepadanya. Sementara itu, menurut Rivai dan Basri (2005:50) kinerja adalah hasil atau tingkat keberhasilan seseorang secara keseluruhan selama periode tertentu dalam melaksanakan tugas dibandingkan dengan standar kerja, target atau target atau kriteria yang telah ditentukan terlebih dahulu dan disepakati bersama. Secara singkat, dapat disimpulkan seperti dalam penelitian Yanuar et al. (2019) kinerja karyawan merupakan hal yang menyangkut dengan hasil tugas yang diselesaikan oleh karyawan itu sendiri. Alat ukur yang digunakan pada penelitian ini sebagai indikator stres kerja yang digunakan oleh Pradhan dan Jena (2017).

\section{Hubungan Stres Kerja Terhadap Kinerja Karyawan}

Terdapat hubungan dimana tingkat stres kerja karyawan yang rendah berpengaruh terhadap kinerja karyawan tersebut meningkat, sedangkan stres kerja karyawan yang tinggi mengakibatkan penurnan kinerja karyawan itu sendiri. Teori Siagian (2010:300) karyawan yang mengalami stres pada umumnya akan mengalami ketegangan dan cendrung menjadi lebih emosional dengan begitu dapat mengakibatkan pada menurunnya kinerja atau dengan kata lain kinerja menjadi tidak optimal. Dalam dunia kerja, masalah stres kerja sering dialami oleh karyawan dan memiliki efek pada kinerja karyawan, sedangkan kinerja karyawan dipengaruhi oleh banyak hal termasuk, stres kerja, budaya kerja dan kepuasan kerja Kazmi et al. (2008) dan Yusnimar \& Mahdani (2015).

\section{Hubungan Kepuasan Kerja Terhadap Kinerja Karyawan}

Kepuasan karyawan dapat terjadi ketika karyawan tersebut merasa terpenuhi kebutuhannya dan hal tersebut dapat memacu karyawan untuk meningkatkan kinerja karyawan. Menurut Wibowo (2014) semakin banyak orang menerima hasil, akan semakin puas, dengan terciptanya kepuasan kerja maka apa yang dilakukan individual terhadap pekerjaan mereka, akan berdampak pada kinerja individual tersebut. Penelitian Ostroff (1992) bahwa kepuasan kerja pada karyawan sebagai sikap karyawan pada pekerjaan secara langsung mengikat 
kebutuhan individu sehingga semakin tinggi kepuasan dan semakin efektif organisasi, artinya bahwa kepuasan kerja mampu meningkatkan efektifitas organisasi.

\section{Kerangka Pemikiran dan Hipotesis}

Penelitian ini juga telah menjelaskan dan memaparkan pada bagian latar belakang bagaimana pengaruh stres kerja dan kepuasan kerja terhadap kinerja karyawan, dan dikuatkan dengan adanya teori-teori oleh para ahli juga pendukung oleh beberapa peneliti terdahulu seperti Hanafi et al. (2018), Steven dan Prasetio (2020), Paais (2018), Annisa (2017), Wulan et al. (2018), Fajriyah (2019), Farooqui dan Nagendra (2014), Daniel (2020), Pandey (2020), Sudiarditha et al. (2020). Oleh sebab itu, kerangka pemikiran yang digunakan penulis dalam penelitian ini ditujukan untuk memperoleh hasil bahwa terdapat pengaruh stres kerja dan kepuasan kerja terhadap kinerja karyawan. Berdasarkan kerangka pemikiran yang telah diuraikan sebelumnya, maka perumusan hipotesis untuk penelitian ini adalah sebagai berikut:

H1: Stres kerja berpengaruh signifikan positif terhadap kinerja karyawan

H2: Kepuasan kerja berpengaruh signifikan positif terhadap kinerja karyawan

\section{METODOLOGI}

Penelitian ini termasuk dalam kategori penelitian kuantitatif. Sementara penelitian ini menggunakan pendekatan non-probability sampling serta menggunakan teknik sampling jenuh. Populasi dari penelitian ini adalah seluruh karyawan atau agen PT International Total Service \& Logistics (ITL) yang tersebar diseluruh penjuru daerah yang ada di Indonesia yang ada dikantor pusat maupun kantor cabang yaitu sebanyak 80 karyawan.

Pengukuran stres kerja sebagai variabel independen dalam penelitian ini, penulis menggunakan pengukuran teori dari Prasetio et al. (2019) dengan indikator tuntutan tugas dan tuntutan pribadi. Pengukuran kepuasan kerja sebagai variabel independen dalam penelitian ini menggunakan indikator sifat pekerjaan, gaji, promosi, pengawasan, dan hubungan antar rekan kerja yang diadopsi dari Robbin dan Judge (Prasetio et al. 2019). Alat ukur kinerja karyawan sebagai variabel dependen pada penelitian ini menggunakan pengukuran teori dari Pradhan dan Jena (2017) dengan indikator menilai kinerja tugas yang diberikan, kinerja adaptive, dan kinerja konsektual. Terdapat total 46 pengukuran variabel yaitu 8 item pernyataan untuk variabel stres kerja, 15 item pernyataan untuk variabel kepuasan kerja, dan 23 item pernyataan untuk variabel kinerja karyawan.

Teknik analisis data yang digunakan dalam penelitian ini menggunakan teknik deskriptif dan kausal dengan menggunakan pengolahan dan pengujian data dengan aplikasi IBM Statistical Product and Service Solutions (SPSS) versi 26. Deskriptif merupakan analisis yang menggambarkan dari karakteristik data tersebut, sedangkan analisis kausal merupakan kaitan dengan studi tentang satu atau lebih variabel mempengaruhi perubahan dalam variabel lain. Adapun analisis jalur juga menjadi dasar dalam pemaparan hubungan langsung dan tidak langsung (Riduwan dan Kuncoro, 2017). Dengan variabel independen dalam penelitian ini yaitu stres kerja (X1) dan kepuasan kerja (X2) dan variabel dependen dalam penelitian ini yaitu kinerja karyawan (Y).

\section{Hasil Analisis Data}

Dari hasil olahan penulis yang berisi uji validitas dengan menggunakan korelasi product momenti terdapat 2 item dari 46 item pernyataan yang tidak valid dikarenakan signifikansi >0,05 yaitu, item 15 pada variabel kepuasan kerja dan item 23 pada variabel kinerja karyawan. 
Pada penelitian ini, hasil dari uji Alpha Cronbach's pada variabel stres kerja sebesar 0,808, kepuasan kerja sebesar 0,795 dan kinerja karyawan sebesar 0,847 menunjukkan angka diatas 0,7 yang berarti bahwa masing masing variabel dikatakan reliabel.

Perhitungan uji asumsi klasik pada penelitian ini berguna sebagai salah satu syarat dalam menggunakan sebuah regresi model dari analisis jalur. Adapun uji asumsi klasik yang akan dilakukan dalam penelitian ini yaitu uji normalitas, uji heterokedastisitas, dan uji multikolinieritas. Hasil dari uji normalitas dengan menggunakan metode uji KolmogorovSmirnov, diketahui Asymp. Sig. (2-tailed) sebesar 0,200. Maka dapat disimpulkan bahwa nilai residual berdistribusi normal dan lolos uji normalitas yang dimana Asymp. Sig. (2-tailed) sebesar 0,200 lebih besar dari 0,05. Hasil uji asumsi klasik selanjutnya yaitu uji heterokedastitas pada penelitian ini menggunakan metode Glejser, menunjukan bahwa nilai Sig. kedua variabel yaitu stres kerja 0,556 dan kepuasan kerja 0,970 lebih besar dari 0,05. Maka dapat disimpulkan bahwa tidak terjadi masalah heterokedastitas. Ujis asumsi klasik terakhir adalah uji multikolinieritas pada Tabel 4.8 didapatai nilai tolerance sebesar 0,790 lebih besar dari 0,20 dan VIF sebesar 1,266 lebih kecil dari 10,00 maka dapat disimpulakan tidak terjadi masalah multikolinieritas atau dalam kata lain, terjadi regresi yang baik antar variabel bebas.

Berdasarkan data primer yang di olah tabel 1 didapatkan nilai hasil koefisien determinasi $\left(\mathrm{R}^{2}\right)$ sebesar 0,334 atau sama dengan $33,4 \%$. Nilai tersebut mengandung arti bahwa variabel stres kerja dan kepuasan kerja secara bersama sama mempengaruhi variabel kinerja karyawan sebesar 33,4\% sedangkan sisanya $66,6 \%$ dipengaruhi oleh variabel lain atau variabel yang tidak diteliti pada penilitian ini.

Tabel 1

Hasil Koefisien Determinasi $\left(\mathbf{R}^{2}\right)$

\begin{tabular}{ll|r|r|r} 
& & \multicolumn{2}{c}{ Model Summary } \\
Model & R & R Square & $\begin{array}{c}\text { Adjusted R } \\
\text { Square }\end{array}$ & $\begin{array}{l}\text { Std. Error of } \\
\text { the Estimate }\end{array}$ \\
\hline 1 & $.578^{\mathrm{a}}$ & .334 & .316 & 9.975 \\
\hline
\end{tabular}

a. Predictors: (Constant), Kepuasan Kerja, Stres Kerja

Uji hipotesis dalam penelitian ini digunakan untuk mengetahui signifikansi variabel bebas terhadap variabel terikat dengan menggunakan software IBM SPSS Versi 26.

Pengujian secara simultan dengan analisis uji f berdasarkan data yang diolah, terpapar hasil Anova pada Tabel 2, ditemukan bahwa hubungan stres kerja dan kepuasan kerja dengan kinerja karyawan signifikan dengan nilai signifikansi $0,00<0,05$. Diperoleh juga $F_{\text {hitung }}>F_{\text {tabel }}$ sebesar 19,267 > 3,11 yang berarti stres kerja dan kepuasan kerja secara simultan atau bersamaan berpengaruh signifikan terhadap kinerja karyawan. 
Tabel 2

Uji Signifikansi Simultan (Uji F)

\begin{tabular}{llr|r|r|r|r}
\multicolumn{7}{c}{ ANOVA $^{\mathrm{a}}$} \\
Model & Sum of Squares & df & Mean Square & \multicolumn{1}{c}{ F } & \multicolumn{1}{c}{ Sig. } \\
\hline 1 & Regression & 3833.789 & 2 & 1916.895 & 19.267 & $.000^{\mathrm{b}}$ \\
\cline { 2 - 7 } & Residual & 7660.961 & 77 & 99.493 & & \\
\cline { 2 - 7 } & Total & 11494.750 & 79 & & \\
\hline
\end{tabular}

a. Dependent Variable: Kinerjaa Karyawan

b. Predictors: (Constant), Kepuasan Kerja, Stres Kerja

Berdasarkan data yang diolah, terpapar hasil koefisien uji t pada Tabel 3 diketahui jika nilai Sig. $<0,05$ atau $t_{\text {hitung }}>t_{\text {tabel }}$ dalam penelitian ini sebesar 1,994 maka terdapat pengaruh antar variabel independen terhadap variabel dependen. Sebaliknya jika nilai Sig. > 0.,05 atau $t_{\text {hitung }}<\mathrm{t}_{\text {tabel }}$ dalam penelitian ini sebesar 1,995 maka tidak terdapat pengaruh antar variabel independen terhadap variabel dependen.

Pada Tabel 3 ditemukan bahwa nilai stres kerja sebesar Sig. 0,238 $>0,05$ dan $t_{\text {hitung }}<t_{\text {tabel }}$ yaitu sebesar $-1,190<1,944$ hal ini berarti menunjukan bahwa stres kerja tidak terdapat pengarauh terhadap kinerja karyawan. Diperlihatkan juga pada Tabel 3 yaitu kepuasan kerja dengan nilai signifikansi $0,000<0,05$ dan $t_{\text {hitung }}>t_{\text {tabel }}$ dengan nilai $4,870>1,994$, hal ini berarti menunjukan bahwa kepuasan kerja terdapat pengaruh secara signifikan terhadap kinerja karyawan.

\section{Tabel 3}

\section{Hasil Uji Signifikansi Parsial (Uji T)}

\begin{tabular}{|c|c|c|c|c|c|c|}
\hline \multicolumn{7}{|c|}{ Coefficients $^{a}$} \\
\hline & & \multicolumn{2}{|c|}{ Unstandardized Coefficients } & \multirow{2}{*}{$\begin{array}{c}\text { Standardized } \\
\text { Coefficients } \\
\text { Beta }\end{array}$} & \multirow[b]{2}{*}{$\mathrm{t}$} & \multirow[b]{2}{*}{ Sig. } \\
\hline \multicolumn{2}{|c|}{ Model } & $\mathrm{B}$ & Std. Error & & & \\
\hline \multirow[t]{3}{*}{1} & (Constant) & 65.709 & 12.441 & & 5.282 & .000 \\
\hline & Stres Kerja & -.202 & .170 & -.125 & -1.190 & .238 \\
\hline & Kepuasan Kerja & .696 & .143 & .510 & 4.870 & .000 \\
\hline
\end{tabular}

a. Dependent Variable: Kinerjaa Karyawan

Maka didapati hasil pengujian hipotesis dari penelitian ini pada tabel 4 sebagai berikut:

Tabel 4 Hasil Pengujian Hipotesis

\begin{tabular}{|c|c|c|}
\hline Kode & Hipotesis & Hasil \\
\hline H 1 & $\begin{array}{c}\text { Terdapat pengaruh stres kerja terhadap kinerja } \\
\text { karyawan }\end{array}$ & Ditolak \\
\hline H 2 & $\begin{array}{c}\text { Terdapat pengaruh kepuasan kerja terhadap } \\
\text { kinerja karyawan }\end{array}$ & Tidak Ditolak \\
\hline
\end{tabular}


Adapun pengaruh langsung dan tidak langsung, besarnya pengaruh stres kerja dan kepuasan kerja terhadap kinerja karyawan pada PT International Total Service \& Logistics dihitung sesuai yang tercantum pada Tabel 5. Hasil temuan penelitian bahwa stres kerja memiliki kontribusi yang positif terhadap tinggi rendah kinerja karyawan sebesar $1,5 \%$ disisi lain kepuasan karyawan memiliki kontribusi yang positif terhadap tinggi rendahnya kinerja karyawan sebesar $26 \%$.

Tabel 5

Pengaruh Langsung dan Tidak Langsung

\begin{tabular}{|c|c|c|c|c|c|}
\hline \multirow[t]{2}{*}{ Variabel } & \multirow{2}{*}{$\begin{array}{c}\text { Koefisien } \\
\text { Jalur }\end{array}$} & \multicolumn{3}{|c|}{ Kontribusi } & \multirow{2}{*}{$\begin{array}{c}\text { Kontribusi } \\
\text { Bersama }\end{array}$} \\
\hline & & Langsung & $\begin{array}{c}\text { Tidak } \\
\text { Langsung }\end{array}$ & Total & \\
\hline $\mathbf{X}_{1}$ & $-0,125$ & $-0,125$ & - & $1,5 \%$ & \\
\hline $\mathbf{X}_{2}$ & 0,510 & 0,510 & - & $26 \%$ & \\
\hline $\mathbf{E}$ & 0,816 & 0,816 & - & $66,6 \%$ & \\
\hline$X_{1} \operatorname{dan} X_{2}$ & & & & & $33,4 \%$ \\
\hline
\end{tabular}

\section{DISKUSI}

Pada hipotesis pertama ini telah dibuktikan bahwa stres kerja tidak terdapat pengaruh secara signifikan terhadap kinerja karyawan. Meskipun telah memenuhi syarat, yakni telah lolos uji asumsi klasik seperti nilai residual berdistribusi normal dan lolos uji normalitas, dan dinyatakan bahwa tidak terjadi masalah heterokedastitas, juga tidak terjadi masalah multikolinieritas atau dalam kata lain terjadi regresi yang baik antar variabel bebas. Namun, berdasarkan hasil nilai Uji T menyatakan bahwa hipotesis tidak dapat diterima atau ditolak dengan hasil nilai Sig. 0,238 $>0,05$ dan $t_{\text {hitung }}<t_{\text {tabel }}$ yaitu sebesar $-1,190<1,944$. Sedangkan, pada hipotesis yang kedua ini telah membuktikan bahwa kepuasan kerja terdapat pengaruh secara signifikan terhadap kinerja karyawan. Hasil penelitian ini terbukti dari nilai uji T dengan nilai signifikansi $0,000<0,05$ dan $t_{\text {hitung }}>t_{\text {tabel }}$ dengan nilai $4,870>1,994$.

\section{PENUTUP}

Berdasarkan dari pengolahan data, pembahasan, serta pembuktian dengan berbagai macam uji yang telah dilakukan atas penelitian pengaruh stres kerja dan kepuasan kerja terhadap kinerja karyawan pada PT International Total Service \& Logistics, maka dapat disimpulkan dengan beberapa hal berikut ini:

1. Stres kerja tidak berpengaruh secara signifikan terhadap kinerja karyawan.

2. Kepuasan kerja berpengaruh positif secara signifikan terhadap kinerja karyawan.

Saran dalam penelitian ini ditujukan untuk perusahaan dan peneliti selanjutunya yang diuraikan sebagai berikut:

1. Saran bagi perusahaan: 
a. Meskipun didalam penelitian ini menunjukan bahwa tinggi atau rendahnya stres kerja karyawan tidak berpengaruh terhadap kinerja karyawan, namun akan jadi lebih baik jika perusahaan mampu mengelola stres yang terjadi pada karyawannya.

b. Perusahaan perlu melakukan evaluasi secara berkala terkait kompenasi yang diberikan kepada karyawan, dikarenakan pernyataan pada variabel kepuasan kerja item 3 yang menyatakan perusahaan memliki kebijakan kompensasi lebih baik dari rata-rata perusahaan sejenis terdapat 30 orang ragu ragu cenderung setuju.

c. Dari hasil tanggapan responden terkait pada variabel kepuasan kerja yang telah dipaparkan, secara keseluruhan menjawab dengan rata rata presentase sebesar $75,11 \%$ atau dapat diartikan bahwa tingkat kepuasan kerja karyawan pada PT International Total Service \& Logistics tinggi, maka dari itu sudah sebaiknya perusahaan mencoba untuk mempertahankan dan memelihara rasa kepuasan karyawan karyawan karena jika karyawan merasa puas dengan apa yang dicapainya maka karyawan tersebut akan menunjukan kinerja yang optimal.

2. Saran bagi penulis selanjutnya adalah menambahkan variabel bebas lainnya yang belum digunakan dalam penelitian ini dengan melihat fenomena yang terjadi dimasa yang akan datang terkait kinerja karyawan.

\section{DAFTAR PUSTAKA}

Annisa, N. N., Setyawan, D., Setyawan, A. A., \& Susila, I. S. (2017). Pengaruh Stres Kerja Terhadap Kinerja Karyawan Dengan Kepuasan Kerja Sebagai Variabel Intervening (Doctoral dissertation, Universitas Muhammadiyah Surakarta).

Daniel, C.O. (2019). Effects of job stress on employee's performance. The International Journal of Business and Management, 6(2), 375-382.

Fajriyah, N. (2019). ISLAM WORK ETHICS, STRES, KEPUASAN, DAN KINERJA KARYAWAN: SEBUAH PERSPEKTIF (Doctoral dissertation, University Of Muhammadiyah Malang).

Farooqui, M., \& Nagendra, D. (2014). The Impact of Person organization Fit on Job Satisfaction and Perfomance of the Employees. Procedia Economics and Finance, (11)14, 122-129. DOI: https://doi.org/10.1016/S2212-5671(14)00182-8.

Fathoni, Abdurrahmat. 2006. Organisasi dan Manajemen Sumber Daya Manusia. Jakarta: Rineka Cipta.

Georgopoulos, B. S., Mahoney, G. M., \& Jones, N. W., Jr. (1957). A path-goal approach to productivity. Journal of Applied Psychology, 41(6), 345353. https://doi.org/10.1037/h0048473.

Griffin, R. W., \& Moorhead, G. (2013). Organizational Behavior Managing People and Organizations . South-Western: Michael Schenk.

Hanafi, A., Zunaidah, \& Ulfa, M. (2018). The Effect of Job Stress Toward Employee Perfomance Through Job Satisfaction of PT Muara Alam Sejahtera Employees. International Journal of Scientific and Research Publications, (8)8, 1-5. DOI: http://dx.doi.org/10.29322/IJSRP.8.8.2018.p8002.

Hasibuan S. P. Malayu (2003). Manajemen Sumber Daya Manusia. Jakarta: Bumi Aksara.

Hasibuan S. P. Malayu (2013). Manajemen Sumber Daya Manusia. PT. Bumi Aksara: Jakarta.

Hasibuan S. P. Malayu (2013). Manajemen Sumber Daya Manusia. PT. Bumi Aksara: Jakarta.

Herzberg, F., Mausner, B., \& Snyderman, B. (1959). The motivation to work (2nd ed.). NewYork John Wiley. 
Hobfoll, S. E., \& Shirom, A. (1993). Stress and burnout in the workplace: Conservation of resources. In T. Golombiewski (Eds.), Handbook of organizational behavior (pp. 4161). New York:Marcel Dekker.

IMO. (2020) IMO AND THE ENVIRONMENT. (Retrieved March 5, 2021, from International Maritime

Organization:https://wwwcdn.imo.org/localresources/en/OurWork/Environment/Docu ments/IMO\%20and\%20the\%20Environment\%202011.pdf)

Kazmi, R., Amjad, S., \& Khan, D. (2008). Occupational stress and its effect on job performance. A case study of medical house officers of district Abbottabad. Journal of Ayub Medical College Abbottabad, 20(3), 135-139.

Lingga, M. A. (2019, July 22). SDM Unggul Mampu Dongkrak Daya Saing Nasional. https://money.kompas.com/read/2019/07/22/150640726/sdm-unggul-mampu-dongkrakdaya-saing-nasional, pp. 1-2.

Ma, Vi-Anne, Huey-Wen Koh, dan Thiam-Yong Kuek, 2012, Exploring The Relationship Among Job Performance, Satisfaction, and Stress: A Conceptual Framework of Malaysia Higher Learning Institutions. www.internationalconference.com.my.

Malik, P. (2019, September 18). The Essential Human Resources Problem To Be Solved. https://www.forbes.com/sites/forbeshumanresourcescouncil/2019/09/18/the-essentialhuman-resources-problem-to-be-solved, pp. 1-3.

Mangkunegara, A.A. Anwar Prabu, 2007. Manajemen Sumber Daya Manusia Perusahaan. PT. Remaja Rosdakarya, Bandung.

Masman, Ronnie R., and Ary S. Pamungkas. "Analisis Pengaruh Kepemimpinan Transformasional, Kepemimpinan Transaksional Dan Motivasi Terhadap Kepuasan Kerja." Jurnal Manajemen Untar, vol. 17, no. 1, 2013.

McNamara. (1999). Job satisfaction. Retrieved April 2, 2021, [Online] Available: http:// www.managementhelp.org/prsn_wl1/job_stfy.htm.

Ostroff, Cheri. (1992). The Relationship Between Satisfaction, Attitudes, and Performance: An Organizational Level Analysis. Journal of Applied Psychology. 77. 963-974. DOI: 10.1037/0021-9010.77.6.963.

Paais, M. (2018). Effect of work stress, organization culture and job satisfaction toward employee performance in Bank Maluku. Academy of Strategic Management Journal, 17(5), 1-12.

Pandey, D. L. (2020), "Work Stress and Employee Performance: An Assessment of Impact of Work Stress", International Research Journal of Human Resource and Social Sciences, Vol. 7 Issue. 05, pp. 124-135.

Pincherle, G. (1972). Fitness for Work: Assessment of the Relationship between Stress and Work Performance. Proceedings of the Royal Society of Medicine, 65(4), 321-324. DOI: https://doi.org/10.1177/003591577206500403.

Pradhan, R. K., \& Jena, L. K. (2017). Employee Performance at Workplace: Conceptual Model and Empirical Validation. Business Perspective and Research, 69-85. DOI: https://doi.org/10.1177/2278533716671630

Prasetio, A. P., Luturlean, B. S., \& Agathanisa, C. (2019). Examining Employee's Compensation Satisfaction and Work Stress in A Retail Company and Its Effect to Increase Employee Job Satisfaction. International Journal of Human Resource Studies, 9(2), 239-265. DOI:10.5296/ijhrs.v9i2.14791.

Riduwan, \& Kuncoro, E. A. (2017). Path Analysis (Analisis Jalur). Bandung: Alfabeta.

Robbins, S.P. 2007. Perilaku Organisasi. Jakarta: PT. Macanan Jaya Cemerlang

Robbins, S.P., and Judge, T.A. 2015. Organizational Behavior. Sixteenth edition. Perason; New York. 
Robbins, Stephen P., \& Judge, Timothy A. (2008). Perilaku Organisasi Buku 2. Jakarta: Salemba Empat.

Shahu, R., \& Gole, S. V. (2008). Effect of job stress and job satisfaction on performance: An empirical study. AIMS International Journal of Management, 2(3), 237-246.

Siagian, Sondang. P, 2010, Manajemen Sumber Daya Manusia. Cetakan Kesebelas. Jakarta:Rineka Cipta.

Steven, H. J., \& Prasetio, A. P. (2020). Pengaruh Stres Kerja Dan Kepuasan Kerja Terhadap Kinerja Karyawan. Jurnal Penelitian IPTEKS, 5(1), 78-88.

Sudiarditha, I.K.R., Mahmud, A., Susita, D., Sariwulan, T., Hidayat, N., Suparno,, Wangi, R.M. (2020). Exploring work stress and burnout in employees in the banking industry. International Journal of Innovation, Creativity and Change, 13(4), 1045-1065.

Veithzal Rivai \& A.F.M Basri. 2005. Performance Appraisal Sistem yang Tepat Untuk Menilai Kinerja Karyawan Dan Meningkatkan Daya Saing Perusahaan. PT Raja Grafindo Persada. Jakarta.

Wibowo, 2014, Manajemen Kinerja. Edisi: 5. Jakarta: Rajawali Pers.

Wulan, D. P. A., Alam, S., \& Umar, F. (2018). Pengaruh Stres Kerja dan Motivasi Terhadap Kepuasan dan Kinerja Karyawan PT PLN (Persero) Area Merauke. Hasanuddin Journal of Applied Business and Entrepreneurship, 1(2), 1-14.

Yanuar, Y., Lego, Y., Masman, R.R. (2019). Job Performance and Government Banks: Evidence from Indonesia. International Journal of Innovation, Creativity and Change. 6(11), 197-212.

Yusnimar, M. Y. \& Mahdani. (2015). Influence of organizational culture and work stress on job satisfaction and its impact on the performance of employees of PT. Aceh bank. Postgraduate Management Journal Syiah Kuala University, 4(1), 135- 143. 